\title{
Heimkehr eines verlorenen Autographen
}

Die Antiquariatsmesse in Ludwigsburg ist für die WLB jedes Jahr ein gesetzter Termin. Alljährlich halten die Sammlungen nach relevanten Büchern, Plakaten, Porträts, Karten oder anderen Medien Ausschau. Oft sind interessante Stücke dabei, die wenn alles gut läuft - für die WLB erworben werden können. Überraschungen sind eher selten. In diesem Jahr staunten die Mitarbeiter der Bibliothek für Zeitgeschichte (BfZ) jedoch nicht schlecht, als sie in den Messekatalog schauten: Angeboten wurde dort ein Brief des Dichters Gottfried Benn "An die 48 Weltkriegsbücherei, Stuttgart".
Nach Kontaktaufnahme mit dem Antiquar, der den Autograph zum Kauf anbot, wurde schnell gewiss, was bis dahin Vermutung war: das Stück stammt aus den Akten der Weltkriegsbücherei, der heutigen BfZ. Der Brief ist nicht nur an die Weltkriegsbücherei gerichtet, sondern enthält überdies einen Eingangsstempel mit Datum, wie er auch sonst in den Akten der BfZ zu finden ist. Ein handschriftliches Zeichen deutet zudem darauf hin, dass der damalige Direktor Friedrich Felger den Eingang abgezeichnet und das Datum des Antwortschreibens vermerkt hat. Doch wie gelangte dieses Schriftstück aus den

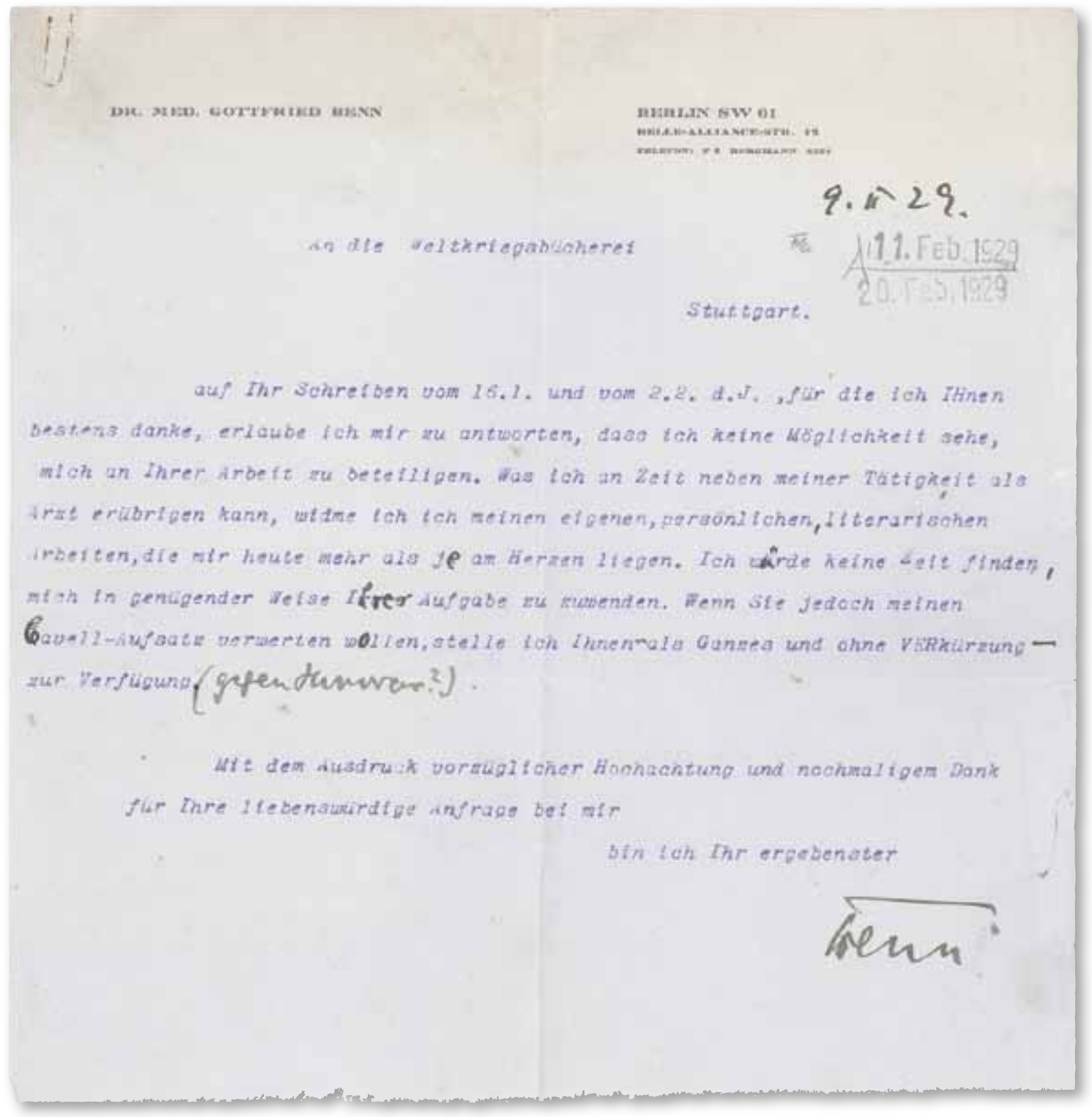


Akten auf den Markt? Nach einigen Recherchen lässt sich der Vorgang wie folgt rekonstruieren: Felger hat den Brief offensichtlich mit nach Hause genommen, wo er bis zu seinem Tod im Jahr 1960 in seinen Unterlagen verblieb. Aus dem Nachlass seiner Tochter gelangte er jetzt zum Verkauf.

Doch wie kam Felger dazu, das Schreiben an sich zu nehmen? Diese Frage führt uns zu dessen Inhalt. Mit seinem auf mintgrünem, dünnem Papier verfassten Brief antwortete der deutsche Arzt, Dichter und Essayist Gottfried Benn (1886-1956) auf ein Schreiben mit der Bitte um Mitarbeit bei der Weltkriegsbücherei. Benns maschinenschriftliche und mit handschriftlichen Verbesserungen, Ergänzungen und Unterschrift versehene Antwort fällt wie folgt aus:

„auf Ihr Schreiben vom 16.1. und vom 2.2. d.J., für die ich IHnen [sic!] bestens danke, erlaube ich mir zu antworten, dass ich keine Möglichkeit sehe, mich an Ihrer Arbeit zu beteiligen. Was ich an Zeit neben meiner Tätigkeit als Arzt erübrigen kann, widme ich meinen eigenen, persönlichen, literarischen Arbeiten, die mir heute mehr als je am Herzen liegen. Ich würde keine Zeit finden, mich in genügender Weise Ihrer Aufgabe zu zuwenden. Wenn Sie jedoch meinen Cavell-Aufsatz verwerten wollen, stelle ich Ihnen - als Ganzes und ohne Verkürzung - zur Verfügung. (gegen Honorar?)"

In welcher Form sich Benn an der Arbeit der Weltkriegsbücherei beteiligen sollte, ist nicht bekannt, da die vorangegangenen Schreiben an Benn nicht überliefert sind. Rekonstruieren lässt sich aber der von ihm erwähnte "Cavell-Aufsatz". 1930 gab Felger im Auftrag der Weltkriegsbücherei den 640 Seiten starken Sammelband „Was wir vom Weltkrieg nicht wissen" heraus, in dem er Benns Aufsatz abdruckte: „Wie Miß Cavell erschossen wurde. Bericht eines Augenzeugen über die Hinrichtung der englischen Krankenschwester".

Die Weltkriegsbücherei war 1915 als Sammlung zum Ersten Weltkrieg gegründet worden. Auch nach 1918 setzte sie sich intensiv mit dem Krieg auseinander, unter anderem im Rahmen einer Vortragsreihe, einer Tagung und mehreren Ausstellungen, die Felger kuratierte. Insbesondere die alliierte Propaganda interessierte ihn. Benn wiederum war während des Krieges im Gouvernement Brüssel als
Oberarzt eingesetzt gewesen. Am 12. Oktober 1915 musste er der Hinrichtung der britischen Krankenschwester Edith Cavell beiwohnen, die als Fluchthelferin von einem deutschen Militärgericht zum Tode verurteilt worden war. Der Fall bildete eine Steilvorlage für die alliierte Propaganda. Die bevorstehende Aufführung eines Films über Cavell veranlasste Benn 1928, den Vorgang aus seiner Sicht im Stil einer Reportage zu dokumentieren. Die Kritik an der drakonischen Bestrafung einer Frau wies er zurück: „Sie hatte als Mann gehandelt und wurde von uns als Mann bestraft." Diesen fünfseitigen Bericht, den er bereits ein Jahr zuvor in einer Berliner Zeitung ${ }^{1}$ veröffentlicht hatte, stellte er nun der Weltkriegsbücherei zur Verfügung.

Der Weltkriegsbücherei war es also gelungen, einen schon damals bekannten Schriftsteller für ihren Sammelband zu gewinnen, in dem ansonsten vor allem Militärs zu Wort kamen. Zur Entstehungsgeschichte des Werks haben sich in der BfZ leider keine Akten erhalten. Vielleicht hat Felger auch den gesamten Schriftverkehr zu diesem Buch an sich genommen, schließlich war er für die Publikation verantwortlich, wenn auch im Auftrag der Weltkriegsbücherei.

Erfreulicherweise konnte eine einvernehmliche Regelung getroffen werden, sodass das Schreiben nun wieder an seinen ursprünglichen Bestimmungsort zurückgekehrt ist. Der Text des Briefes ist zwar recht kurz, doch er spiegelt einen interessanten Aspekt der Geschichte der Bibliothek für Zeitgeschichte wider. Das Autograph ergänzt zudem den Nachlass von Gottfried Benn im Deutschen Literaturarchiv Marbach.

Christian Westerhoff 